sure, however, that he has produced a book which will be useful as a reference source for many years to come.

The authors deal mainly with the properties of the viruses themselves and with host-virus relationships at a molecular level. When appropriate there are small sections indicating the relevance of each group of viruses to human or animal diseases. It is anticipated, therefore, that this work would appeal to the research worker in academic or clinical virology, to biochemists and molecular biologists, rather than to the clinician who wishes to know more about virus infections.

Volume 2 is to contain five reviews of D.N.A. viruses again by well known authors and will be eagerly awaited.

\section{Motor Neurone Disease}

Edited by F. Clifford Rose, Pp. 147, hard cover, illustrated. Pitman Medical, Tunbridge Wells, 1977. £7.00.

This book is the product of a Symposium organized by the Medical Society of London out of the Mansell Bequest. The presentations by a number of neuroscientists are pleasantly informal and of very variable length and depth. On the one hand we descend to the level of differential diagnosis of wasted hand and foot drop. At the other end we have eleven pages of Bradley's review of axonal transport, with over one hundred and twenty references. No doubt those attending and listening to each other derived some benefit from this meeting. However, whether their considerations deserve publication at the cost of $£ 7.00$ for about a hundred and twenty pages of text (leaving out illustrations) is another matter, in these days of shortage of both paper and money. Librarians need not shed any tears if they feel unable to acquire this book - most reviewers will be only too happy to pass it on to them.

\section{Principles of Surgical Oncology}

Edited by Ronald W. Raven. Pp. $x+509$, illustrated, hard cover. Baillière Tindall, London, 1977. £28.00.

Surgeons who are dealing with the day-to-day practical clinical problems of patients with malignant disease are all too aware of the need of a broad understanding of the basic principles of the subject. They need to be kept up to date with the latest advances in diagnostic techniques, they want to know the latest news about immunology, chemotherapy and hormone treatment. They are anxious to hear of any news of aetiology and thus of prevention of malignant disease. Ronald Raven has performed a valuable service by collecting together a team of a couple of dozen experts who present authoritative yet readable accounts of the most recent developments in therapeutic knowledge and practice in oncology. Among the topics considered are carcinogens and carcinogenesis, the biochemistry of human malignant diseases, epidemiology, pathology, diagnostic techniques and the use of computers. The chapters on radiotherapy and chemotherapy are of particular interest in providing the background knowledge to the use of these treatment modalities. The book is attractively produced, easy to read and provided with extensive and up-to-date bibliography. It can be warmly recommended to practising surgeons as an excellent review of the fundamental principles underlying surgical oncology.

\section{Psychiatric Hospitals Viewed by Their Patients}

By Winifred Raphael. Pp. 50, soft cover. King's Fund Books, 1977. £3.75.

The King Edward's Hospital Fund and Winifred Raphael in particular are to be congratulated for these two publications which attempt to reverse the tendency of hospitals to become more concerned about themselves than the community, by presenting the views of the patients who use the hospitals.
Unfortunately, both studies are restricted to in-patient 3 samples and are spread over a period from 1967 to 1974.

'Patients and their Hospitals' looks at patient criticisms for all general hospital wards except obstetric, paediatric, geriatric and psychiatric. Interestingly, the levels of criticism were significantly higher when the sampling was done when the patient was actually in hospital as opposed to after dis-등 charge, and for both these surveys it is likely that the level of $\bar{\sigma}$ complaints as a whole are going to be influenced by the 'halo' $\bar{S}$ effect due to the emotive nature of serious illness. The $\overparen{D}$ general hospital patients expressed most concern about the $\varrho$ sanitary accommodation, lack of privacy and the poor temperature control in the ward. Psychiatric patients, although often in conditions which were much worse than in the. general hospital, had fewer complaints, and it may well be $\overrightarrow{\vec{c}}$ that hospitals with the largest number of complaints in the $\vec{\omega}$ psychiatric survey were more effective in preventing the institutionalization and apathy of their patients. An indica-e tion of this effect was that short-stay patients were con- 3 stantly more critical than long stay. The figure that $83 \%$ of long-stay patients were satisfied with the arrangements for $\perp$ privacy on the ward and sanitary areas is surely a comment $\rightarrow$ on the apathy of the patients rather than on the adequacies of resource. Each booklet also provides instructions for in administering the questionnaire.

When one drives into a hospital in which all the car parks are restricted for the use of staff alone, one realizes that these 0 booklets should find a place in every ward sister's office and $כ$ every administrator's desk.

\section{Short Practice of Surgery (17th Edition)}

By BAILEY and LOVE (Revised by A. J. (a) Rains and H. David Ritchie.) Pp. $x x+1352$, hard cover, illus:
trated. H. K. Lewis, London, $1977 . £ 17.50$.

The 17th edition of 'Bailey and Love' ensures its unrivalled position as the most widely read textbook of surgery in the $\bar{\partial}$ world and it is now heading towards a million copies, something to which a paperback novelist might dream of achiev- $\frac{O}{D}$ ing. It has been translated into Spanish, Italian and Turkish $\varrho$ and has been in continuous publication for 45 years. Its $\overrightarrow{\overrightarrow{0}}$ success is based on its numerous and interesting illustrations, $\frac{0}{3}$ a clearly written text and a lively presentation. The present edition appears after only two years and keeps the book well up to date with modern technological advances such as? endoscopic retrograde catheterization of the pancreatic duct $\bar{D}$ and EMI scanning. A large team of experts from British 3 teaching hospitals ensures that a reliable and continually up-dated account of current surgical practice is given.

This outstanding book can be recommended without hesitation as the best British undergraduate text in surgery but, $\bigcirc$ in addition, it provides the most suitable single volume to cover the topics required by candidates studying for the 0 Fellowship examinations of the various surgical colleges.

\section{Somatic and Visceral Sensory Mechanisms}

British Medical Bulletin, Vol. 33, No. 2, May 1977.

Pp. 89-182, soft cover, illustrated. British Council, $\mathbb{N}$ London, 1977. $£ 4.50$ (UK), $£ 5.00$ (Other Countries).

This number maintains the high standard which we have 0 come to accept in the B.M.B. It was planned by G. S. Brindley, A. Iggo and T. P. S. Powell. It covers a wide range of topics in sensory anatomy and physiology ranging from a review of Head's work by $R$. A. Henson to a section on? opiate peptides by J. Hughes and $\mathbf{H}$. W. Kosterlitz.

The heavy emphasis on animal anatomy and physiology is $\bar{O}$ a reflection of the difficulty of making objective observations $\overrightarrow{\mathbb{D}}$ and recordings in the human subject. In this connection it was $\frac{\mathcal{P}}{\mathbb{D}}$ 
odd to find no reference to the work of Keele and Armstrong in the section on cutaneous hyperalgesia, nor could any reference be found to Ridley's work on Meissner's corpuscles in man.

Clinicians will find much to interest them in this issue.

\section{System of Orthopaedics and Fractures (3th Edition)}

By A. Graham Apley. Pp. $x+477$, hard cover, illus-

trated. The Butterworth Group, Sevenoaks, 1977. £15.95.

This book deserves to be in its fifth edition. It provides a very clear and accurate account of the present day approach to the common problems of orthopaedic and traumatic surgery. To do this within the confines of 459 pages is no mean feat. This has been done by dividing the contents into three main sections, namely general orthopaedics, regional orthopaedics and injuries. Each part is tidily presented with short crisp sentences and generously illustrated with appropriate photographs and radiographs. It is right up-to-date with references even from 1977. The author who is well known for his talents as a teacher has produced a book which will remain popular amongst undergraduate and F.R.C.S. candidates for many years to come.

\section{Notice}

WORLD CONFERENCE ON CLINICAL PHARMACOLOGY AND THERAPEUTICS

London 3-9 August 1980

THE FIRST WORLD CONFERENCE ON CLINICAL PHARMACOLOGY AND THERAPEUTICS, under the sponsorship of the International Union of Pharmacology and the British Pharmacological Society, will take place in London in 1980.

Further information may be obtained from:

Conference Associates CPT.

34 Stanford Road,

London, W8 5PZ. 